\title{
DIVERTICULOSIS - THE CLINICAL AVIATION MEDICINE ASPECT AND AEROMEDICAL CONCERNS
}

\author{
Lech KOPKA ${ }^{1}$, Ewelina ZAWADZKA-BARTCZAK², Leopold BAKOŃ ${ }^{3}$, Łukasz JAŁOCHA² \\ ${ }^{1}$ Centre of Experimental Medicine, Military Institute of Aviation Medicine, Warsaw, Poland \\ ${ }^{2}$ Department of Internal Disease, Military Institute of Aviation Medicine, Warsaw, Poland \\ ${ }^{3}$ Department of Radiology, Military Institute of Aviation Medicine, Warsaw, Poland
}

Source of support: Own sources

Author's address: L. Kopka, Centre of Experimental Medicine, Military Institute of Aviation Medicine, Krasińskiego 54/56 Street, 01-755 Warsaw, Poland, e-mail: Ikopka@wiml.waw.pl

Abstract: This publication discusses the clinical aspects and aeromedical concerns of diverticular disease. A case of a 49-year-old supersonic aircraft pilot diagnosed with diverticulosis 19 years earlier served as an inspiration for this position paper. Upon consideration, particular attention was paid to the diagnostics, the likelihood of extreme flight factors influencing the course of diverticulosis and related prognostic implications. The conclusion contains an aeromedical disposition decision concerning highly maneuverable aircraft pilots diagnosed with diverticular disease resulting from the presented case and theoretical considerations.

Keywords: supersonic pilots, accelerations, high altitude 
Kopka L. et al. - Dierticulosis - the clinical...

\section{INTRODUCTION}

Diverticulosis of the colon is one of the most common disorders of the gastrointestinal tract in Western Europe $[18,24]$. The highest incidence of the disease occurs in Europe, USA and Australia. Studies show that the prevalence of diverticulosis increases with age. It is $<5 \%$ in persons under 40 years of age, $30 \%$ in individuals 60 years old and $50-65 \%$ in persons aged $85[16,17,19]$. Due to this fact, this pathology is relatively rare in the age group of active highly maneuverable aircraft pilots. It should be noted, however, that the data concerning the occurrence of diverticulosis is likely to be underestimated due to the fact that in about $85 \%$ of cases the disease is asymptomatic [3]. The issue raised is of particular importance with regard to highly maneuverable aircraft pilots exposed to hypoxia, high-altitude gas expansion, acceleration, anti-G straining maneuvers and pressure breathing. So, it is connected with flight safety.

The development of aviation medicine and technology has led to a better understanding of the impact of extreme flight conditions on the human body. At the same time, progress in medical technology has led to more precise diagnostic tests for the pilots. Medical boards responsible for flight clearance may be presented with a dilemma as to whether recognize the severity of lesions as directly en- dangering flight safety, or if further flight service will have an impact on the progression of lesions and the development of possible complications. This uncertainty may involve clinically asymptomatic lesions in the spine, the cardiovascular system or the gastrointestinal tract. The exchange of knowledge and opinions concerning aviation medicine is beneficial from the point of view of aeromedical disposition decision and ethics.

An inspiration for this position paper came from a case of a 49-year-old supersonic aircraft pilot suffering from nonspecific complaints and unexpectedly diagnosed with diverticulosis (diagnosed by an x-ray with contrast medium in the intestine) 19 years ago. He was allowed to continue flying once the symptoms subsided. In February 2013, he was hospitalized due to clinical symptoms of diverticular disease (abdominal pain, elevated body temperature, increased leukocyte count and CRP) that required broad-spectrum antibiotic therapy. Six months later, he was hospitalized once again due to pain in the left iliac fossa without fever or elevation in laboratory markers of inflammation. Colonoscopy revealed multiple diverticula in the descending colon and sigmoid, along with discrete signs of inflammation in the vicinity of one of them. A 320-slice abdominal CT $(0.5 \mathrm{~mm}$ helical scan layer thickness) performed after 2 weeks

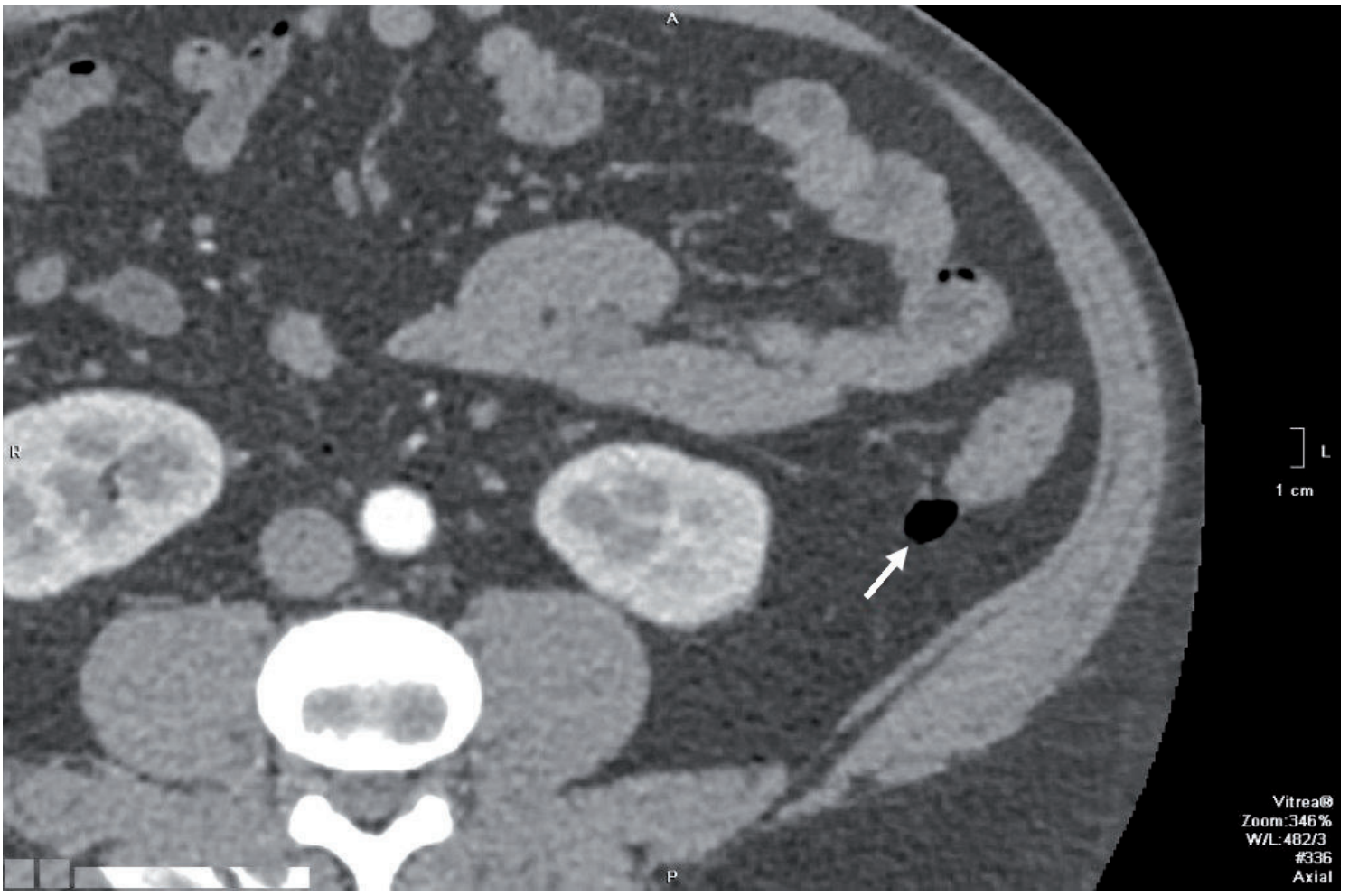

Fig. 1. The first type of diverticula with very thin walls (marked by the red arrow). 


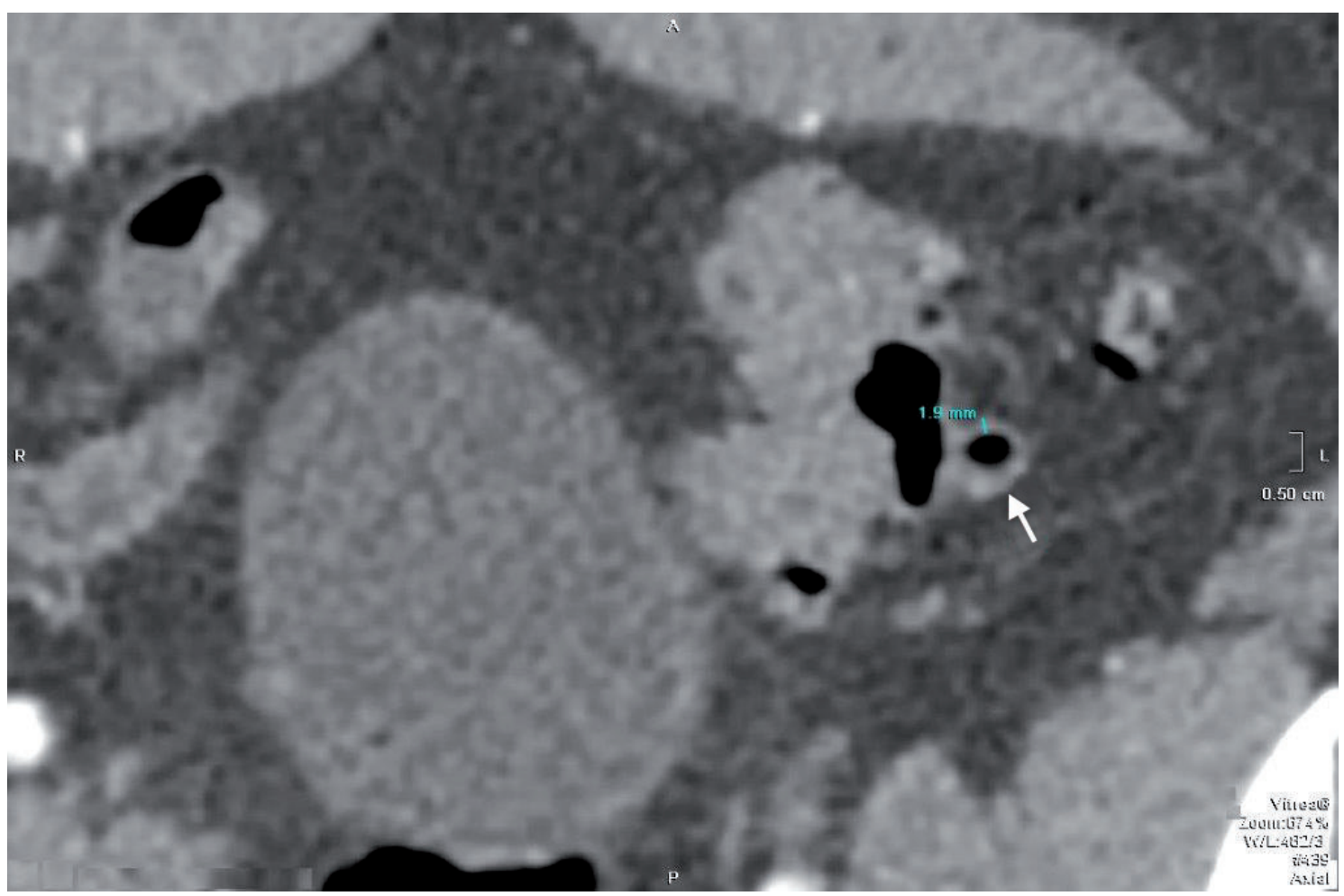

Fig. 2. The second type of diverticula with wall thickness of about 1.8-2 $\mathrm{mm}$ (marked by the red arrow).

of anti-inflammatory therapy, revealed numerous diverticula in the colon, without signs of inflammation. The diverticula were classified into one of three types based on the thickness of the wall (diverticula filled with fecal masses were not considered). The first type included diverticula with very thin walls that remained beyond the scope of the testing method (Fig.1). Approximate air volume in the largest one of them was $4.57 \mathrm{~cm}^{3}$.

The second type were diverticula with wall thickness of about 1.8-2 mm (Fig. 2) and a maximum air volume of $0.5016 \mathrm{~cm}^{3}$.

Third type of diverticula comprised of those with non-uniform wall thickness that represent a combination of the first two types (Fig. 3) and a maximum air volume of $1.274 \mathrm{~cm}^{3}$.

The pathogenesis of diverticulosis is still unknown but multifactorial $[10,20]$. It is caused by the following: low-fiber diet, structural changes in the intestinal wall, increased intraluminal pressure, low physical activity, segmentation and disorders of bowel motility. Abnormal motility may be caused by changes in the number and location of intestinal cells of Cajal [21] as well as by abnormalities in neural transmission [2]. Genetic factors and the process of aging also play an important role [25]. A low-fiber diet leads to the formation of harder stools, which require stronger intestinal contractions and result in hypertrophy of the muscle. A longer intestinal transit time, muscle hyper- trophy and severe contractions cause increased pressure in the intestinal lumen. As a result, intestinal mucosa is pushed out of the membrane in areas of reduced resistance (e.g., blood vessels penetrating the intestine) to form diverticula [9]. Diverticulosis most commonly involves pseudodiverticula, which consist of mucosa and submucosa [24]. True diverticula containing a muscle layer are very rare and are thought to be mostly congenital $[9,24]$. Diverticulosis arise most commonly in the descending colon, because its lumen is the smallest and the change in pressure caused by forceful contractions is the highest [24].

CT of the colon revealed 3 types of diverticula, based on the thickness of the wall. A hypothesis could be made that diverticula with thick walls (Fig. 2) contain a muscle layer and are, therefore, true diverticula. If this hypothesis holds true, another one could be stated, that is diverticula of mixed wall thickness (Fig. 3) are morphologically in transition from true diverticula (Fig. 2) to the typical thin wall diverticula (based on tomographic evaluation) found in diverticulitis (Fig. 1). It seems likely that the predisposing factors, particularly increased intraluminal pressure, gradually displace (quite possibly asymmetrically) the intestinal mucosa beyond the muscular layer. If this hypothesis were proved to be true, it would greatly help address the medico-ethical and aeromedical disposition decision concerning military 


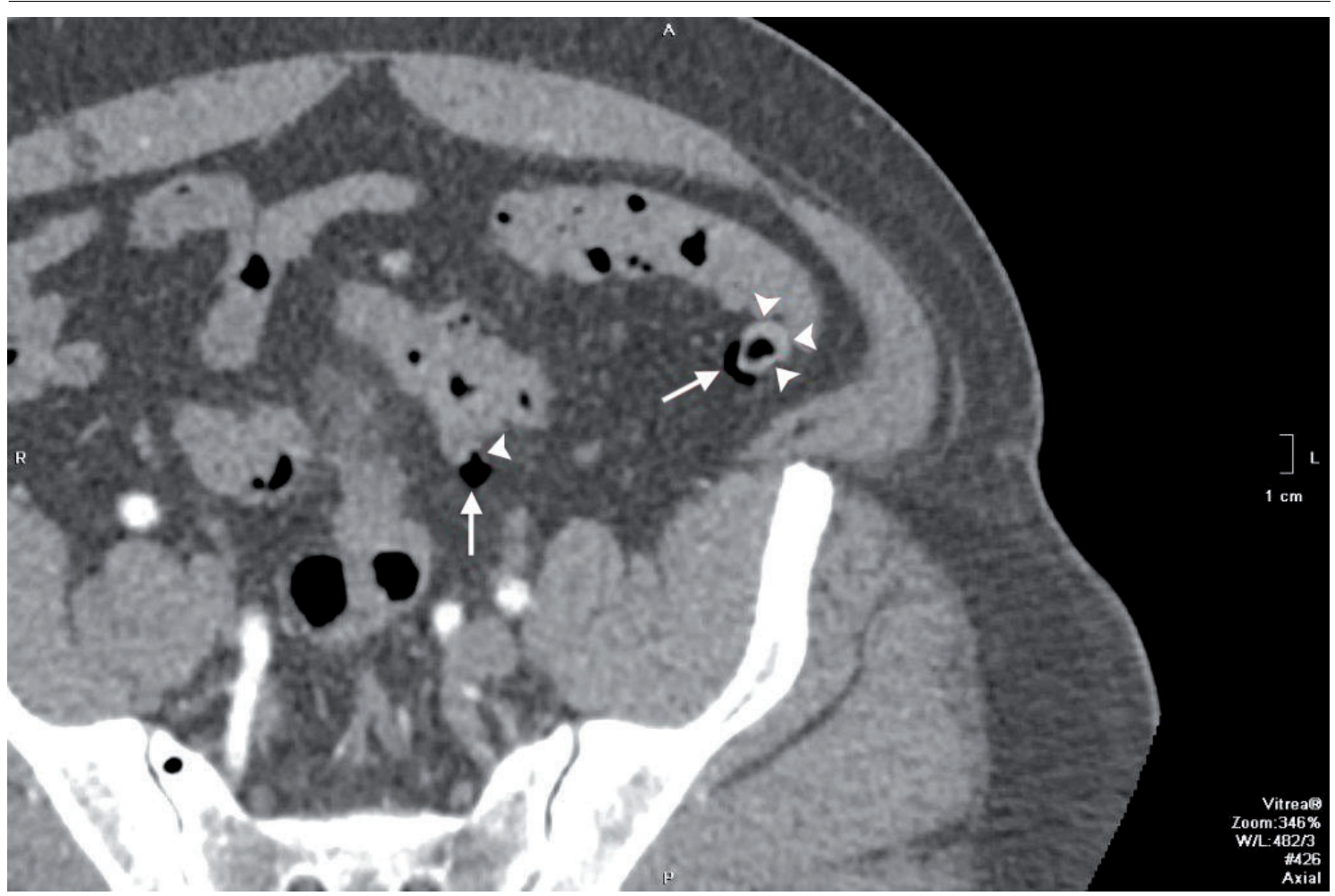

Fig. 3. The third type of diverticula - represents a combination of the first two types (marked by the red arrows).

pilots of highly maneuverable aircraft. Computer-based annual follow-up examination of the abdomen would provide insight into the possible advancement of diverticular morphological changes. Changes in the morphology of thick wall (true?) and "intermediate" diverticula into very thin-wall diverticula (typically pseudodiverticula), are associated with unfavorable and rapid progression of the disease, likely under the influence of extreme flight conditions. Such changes would signify an increased risk of potential perforation of the colon due to increased pressure in the abdominal cavity during flight. Both, acceptance or rejection of the hypothesis is difficult to prove. This would require follow-up computer testing of individuals with diverticulosis over a period of many years, which is impossible to carry out on a large group of pilots.

From a clinical viewpoint, the term "diverticulosis" represents the presence of asymptomatic diverticula in the colon confirmed with imaging studies, whereas "diverticular disease" is the presence of clinical symptoms.

Diverticular disease should be classified as [26]: [1] symptomatic uncomplicated diverticular disease: a single episode of non-specific symptoms, such as lower abdominal discomfort or abdominal pain, bloating, abdominal tenderness, constipation, diarrhea without any sign of inflammation (fever, neutrophilia, phlogosis of diverticula); [3] recurrent symptomatic uncomplicated diverticular disease: more than one attack per year of nonspecific symptoms without signs of inflammation, or [5] complicated diverticular disease: abdominal symptoms associated with signs of inflammation.

A variety of complications may occur in the course of diverticular disease $[15,28]$. The most common one is diverticulitis. The pathogenesis of diverticulitis is not fully understood. However, it is thought that predisposing factors include: low-grade chronic inflammation, gut microbiota abnormalities, toxin exposure within the gut (arising from fecal retention) and intestinal ischemia. Diverticulitis usually follows an uncomplicated course $(75 \%)$. In the remaining cases, it leads to the development of abscess, phlegmon, peridiverticular abscess or diverticular perforation with associated peritonitis [24]. Other complications of diverticulitis may include: narrowing and obstruction of the bowel, inflammation of the surrounding organs, fistulas, bleeding, liver abscess and sepsis [19]. Although diverticular disease is more common among elderly patients, a dramatic rise of its incidence is seen in the younger age groups [14]. Diverticular disease complications are most frequent in obese individuals on low-fiber diet, tobacco smokers, persons with chronic diseases, such as liver cirrhosis, diabetes, renal failure and especially those taking corticosteroids and immunosuppressive drugs [27]. Diverticulitis usually oc- 
curs in an acute or chronic form. The acute form involves a rapid onset and duration of symptoms for about 2 weeks. The chronic type is diagnosed when the symptoms are milder, recurrent and present for more than 6 months. Recurrence with an increased risk of complications occurs in $25 \%$ of patients with diverticulitis [30]. Diagnostic tests include blood counts, acute phase protein (CRP) concentration, CT evaluation or alternatively MRI or ultrasound imaging could be implemented $[6,12,22]$. Colonoscopy should be avoided in the course of acute diverticulitis due to increased risk of perforation but in case of bleeding treatment or chronic colitis, differential diagnosis colonoscopy is suggested [20]. Additionally, the large intestine is difficult to evaluate because of shrinkage, narrowing of the lumen and immobilization (fixation). Following the acute phase, a complete endoscopic examination must be performed to exclude other conditions, such as inflammatory bowel disease and cancer [24].

Diverticulitis affects the patient's quality of life. Recurrence prevention plays an important role. Recommendations include change in diet to increase the amount of fiber consumed, avoidance of foods that create excessive amounts of intestinal gas (carbonated water, carbohydrates, legumes, cabbage) and weight reduction. A change in lifestyle with increased physical activity also plays a vital role. Prophylactic pharmacotherapy remains open to debate $[5,7]$ but rifaximin is suggested [13], efficacy of mesalazin is not confirmed.

\section{THE AVIATION MEDICINE ASPECT}

Under normal conditions, the gastrointestinal tract of a healthy individual contains a few hundred milliliters of free gas [1]. It is produced by fermentation of foods and its chemical composition (carbon, oxygen, hydrogen, nitrogen, methane, hydrogen sulphide) along with the amount accumulated, depend on a person's nutrition and the quantity of air swallowed with saliva and food (this is particularly true of individuals prone to aerophagia).

During the ascent, in the presence of decreased surrounding atmospheric pressure, the volume of gas in the gastrointestinal tract increases gradually and proportionately. The severity and intensity of the illness depend on the amount and rate of gas accumulation, its distribution within the gastrointestinal tract, the anatomic and functional condition of the intestine, the time elapsed since the last meal, the type and degree of abdominal wall tension and abdominal pressure.
Military training flights take place at heights of 6,000-12,000 meters. The airtight cabin of the aircraft maintains correspondingly lower air pressure (depending on the altitude) to reduce the effects of any sudden decompression. Rapid ascent and descent of an aircraft during military training operations causes the volume of intestinal gas to change rapidly. It should be noted that low cabin pressure and the use of technical devices protecting from hypoxia prevent only sudden decompression complications. The volume of gas in the gastrointestinal tract increases by $50 \%$ at 3,000 meters and by $100 \%$ at 7,000 meters, as compared to the original volume at sea level. An increase in gas volume in the gastrointestinal tract during decompression at higher altitudes would be correspondingly greater [11]. It should be emphasized that the impact of rapid decompression on the gastrointestinal tract depends not only on the parameters of decompression (the difference between the initial and final pressure in the cabin, their relative ratio and the duration of decompression) and the initial amount of gas in the intestine, but also on the functional state, and more importantly, the structural changes in the intestinal wall. Expansion of gas in the gastrointestinal tract leads to abdominal distension and elevation of the diaphragm. Distension of the stomach and the intestines causes a feeling of fullness and discomfort in the abdominal cavity [1].

In the course of diverticulosis, the greatest risk of complications associated with supersonic flight is due to increased pressure throughout the intestines and the abdominal cavity. This can cause extreme pain or even intestinal perforation, especially in the setting of a disease process. During rapid decompression, the expanding gas remains mostly in the same location. Thus, in cases of diverticula obstructed by fecal matter, a rapid increase in the volume and pressure of gas accumulated within the enclosed space takes place. Expansion of diverticula containing gas may lead to reflex contraction of the adjacent sections, making it difficult, or even impossible, to propagate and eliminate the gas by natural means.

The force of $+\mathrm{Gz}$ acceleration leads to a downward displacement of tissues and organs, especially those with a range of movement, such as the liver, the bladder and the intestines, resulting in an additional impact on abdominal pressure. Values of venous and abdominal pressure increase in a linear proportion to the rate of acceleration [8]. Additionally, rapid changes in pressure take place when changing the direction of acceleration in the $\mathrm{Gz}$ axis, especially during aerobatic 
maneuvers in the upside-down position: such as a barrel roll, reversed loop, inverted corkscrew and others. An additional increase in abdominal pressure during flight in a highly maneuverable aircraft is caused by Anti-G-Straining Maneuvers (AGSM) performed by the pilots and the pressure exerted by an abdominal pressure compensator, which is part of a pressure suit [29]. One of its tasks is to reduce the harmful effects of high-altitude meteorism.

An increase in intra-abdominal pressure is also stimulated by pressure breathing, resulting in lowering of the diaphragm and an increase in abdominal pressure [23]. The potential impact of vibrations occurring in aviation on diverticular disease is impossible to assess.

\section{AERO-MEDICAL CONCERNS}

Flight safety and aviator's wellness should be taken into account when conducting a medical assessment of a pilot of a super-maneuverable aircraft,. This includes the possibility of structural changes within the diverticula, an increase in the number of diverticula and possible progression of the disease forced by flight factors. Therefore, diverticulosis is an extremely important subject of medical certification and an equally important ethical and medical issue.

Computer test results of the presented case of diverticulosis / diverticular disease suggest that even originally true diverticula with thick walls may transform, under a longstanding influence of harmful factors, into thin-walled pseudodiverticula visible on a CT. There is no doubt that the discussed extreme factors affecting the pilot body, particularly significant and relatively rapid pressure changes within the colon, are a predisposing factor in the progression of morphological changes in diverticulosis of the bowel. Considering the above findings, along with a documented diverticular disease, we believe that pilots of supersonic aircraft should not be allowed to continue to fly.

Pilots may be able to continue their flying duty in cases of asymptomatic diverticulosis detected accidentally, e.g. during prophylactic endoscopy of the colon, provided that they undergo periodic CT screening, taking into account the progression of diverticular wall morphology discussed earlier in this document. Such position may be justified by the fact that the pilot discussed in this publication served in the air force with a diagnosed and asymptomatic diverticulosis of the colon for 19 years without any complications and the hypotheses presented in this work were not sufficiently proven. However, presence or development of diverticulitis with very thin walls, below $0.5 \mathrm{~mm}$ (beyond the capability of accurate $\mathrm{CT}$ assessment), in our opinion, should constitute a contraindication to flying highly maneuverable aircraft. For highly maneuverable aircraft pilot candidates, it may be worth considering performing CT screening of not only the spine, but also the abdominal cavity.

\section{AUTHORS' DECLARATION:}

Study Design: Lech Kopka, Ewelina Zawadzka-Bartczak, Łukasz Jałocha, Leopold Bakoń; Data Collection: Lech Kopka, Ewelina Zawadzka-Bartczak, Łukasz Jałocha, Leopold Bakoń; Manuscript Preparation: Lech Kopka, Ewelina Zawadzka-Bartczak. The Authors declare that there is no conflict of interest.

\section{REFERENCES}

1. Bedell GN, Marshall R, DuBois A, Harris JH. Measurement of the volume of gas in the gastrointestinal tract. Values in normal subjects and ambulatory patients. J Clin Invest. 1956; 35(3):336-345.

2. Bottner M, Wedel T. Abnormalities of neuromuscular anatomy in diverticular disease. Dig. Dis. 2012; 30:19-23.

3. Comparato G, Pilotto A, Franzè A, Franceschi M, Di Mario F. Diverticular disease in the elderly.Dig Dis. 2007; 25(2):151-59.

4. Daniels L, Budding AE, de Corte N. Fecal microbiome analysis as a diagnostic test for diverticulitis. Eur. J. Clin. Microbiol. Infec. Dis. 2014; 33:1927-1936. 
5. Di Mario F, Comparato G, Fanigliulo L, et al. Use of mesalazine in diverticular disease. J Clin Gastroenterol. 2006; 40(3):155159.

6. Feingold D, Steele SR, Lee S, Kaiser A, Boushey R, Buie WD, Rafferty JF. Practice Parameters for the Treatment of Sigmoid Diverticulitis. Task Force of the American Society of Colon and Rectal Surgeons Dis Colon Rectum. 2014; 57:284-294 .

7. Fric $\mathrm{P}$, Zavoral $\mathrm{M}$. The effect of non-pathogenicEscherichia coli in symptomatic uncomplicated diverticular disease of the colon. Eur J Gastroenterol Hepatol. 2003; 15:313-315.

8. Glainster DH, Prior ARJ. The effects of long duration acceleration. In Ernsting J, Nicholson A, Rainford DJ ed: Aviation medicine. Butterworth-Heinemann, Oxford; 1999:128-147.

9. Hulten L, Haboubi NY, Schofield PF. Diverticular disease. Colorectal Dis. 1999; 1:128-136.

10. Kang JY, Melville D, Maxwell JD. Epidemiology and management of diverticular disease of the colon.Drugs Aging. 2004; 21(4):211-28.

11. Khurana I. Environmental physiology. In: Khurana I, ed. Textbook Of Medical Physiology 1rst ed. Noida: Elsevier India. 2006:1236-1237.

12. Köhler L, Sauerland S, Neugebauer E. Diagnosis and treatment of diverticular disease: results of a consensus development conference. The Scientific Committee of the European Association for Endoscopic Surgery. Surg Endosc. 1999; 13:430-436.

13. Lanas A, Ponce J, Bignamini A, Mearin F. One year intermittent rifaximin plus fibre supplementation versus fibre supplementation alone to present recurrence of diverticulitis - a proof of concept study. Dig Liver Dis. 2013; 45:104-109.

14. Makela J, Kiviniemi H, Laitinen S. Prevalence of perforated sigmoid diverticulitis is increasing. Dis Colon Rectum. 2002; 45:955-961.

15. Mendeloff Al. Thoughts on the epidemiology of diverticular disease. Clin Gastroenterol. 1986; 15:855-877.

16. Painter NS, Burkitt DP. Diverticular disease of the colon, a 20th century problem. Clin Gastroenterol. 1975; 4:3-21.

17. Painter NS, Burkitt DP. Diverticular disease of the colon: a deficiency disease of Western civilization. BMJ. 1971; 2:450-54.

18. Parks TG. Natural history of diverticular disease of the colon. A review of 521 cases. BMJ. 1969; 4:639-42.

19. Parks TG. Natural history of diverticular disease of the colon.Clin Gastroenterol. 1975; 4:53-69.

20. Pietrzak A, Bartnik W, Szczepkowski M, Krokowicz P, Dziki A, Reguła J, Wallner G. Polski konsensus interdyscyplinarny dotyczący diagnostyki i leczenia choroby uchyłkowej okrężnicy. Gastroenterologia Kliniczna. 2015; 7:1-19.

21. Shafik A, Shafik AA, El-Sibai O, Shafik IA. Interstitial cells of cajal in patients with constipation due to total colonic inertia. J Invest Surg. 2006; 19(3):147-153.

22. Shrier D, Skucas J, Weiss S. Diverticulitis: an evaluation by computed tomography and contrast enema. Am J Gastroenterol. 1991; 86:1466-1471.

23. Shubrooks SJ Jr. Positive-pressure breathing as a protective technique during +Gz acceleration. J Appl Physiol. 1973; 34:294-298.

24. Stollman N, Raskin JB. Diverticular disease of the colon. Lancet. 2004 Feb 21; 363(9409):631-9.

25. Talbot JM. Role of dietary fiber in diverticular disease and colon cancer. Fed Proc. 1981; 40:2337-42.

26. Tursi A. Acute diverticulitis of the colon current medical therapeutic management. Expert Opin Pharmacother. 2004; 5:55-59.

27. Tyau ES, Prystowsky JB, Joehl RJ, et al. Acute diverticulitis. A complicated problem in the immunocompromised patient. Arch Surg. 1991; 126:855-58.

28. West AB, Losada M. The pathology of diverticulosis coli. J Clin Gastroenterol. 2004; 38(5):11-16.

29. Wood EH, Hallenbeck GA. Voluntary (self-protective) maneuvers which can be used to increase man's tolerance to positive acceleration. Fed Proc. 1946; 5:115.

30. Young-Fadok TM, Roberts PL, Spencer MP, Wolff BG. Colonic diverticular disease. Curr Probl Surg. 2000; 37:457-514.

Cite this article as: Kopka L, Zawadzka-Bartczak E, Jałocha $Ł$, Bakoń L. Diverticulosis - The Clinical Aviation Medicine Aspect and Aeromedical Concerns. Pol J Aviat Med Bioeng Psychol 2018; 24(1): 14-20. DOI: 10.13174/pjambp.06.08.2019.02 